\title{
RELATIONSHIP BETWEEN PARENTAL OCCUPATION, HOME ENVIRONMENT AND ACADEMIC PERFORMANCE OF PUBLIC SENIOR SECONDARY SCHOOL STUDENTS IN SOKOTO STATE, NIGERIA
}

UMAR, MAIMUNA RABO

Dept. of Educational Foundations, Usmanu Danfodiyo University, Sokoto, Nigeria

\begin{abstract}
This paper discussed the relationship between parental background support in relation to occupation, home environment and students' academic performance. The research design adopted for this study was correlation research design. The study was based on Conflict theory, which sees the purpose of education as a means of maintaining social inequality and preserving the power of those who dominate the society. The study was carried out using questionnaire, achievement test and focus group discussions, the questionnaire was researcher designed and it was based on closed ended questions with options of $A, B, C, D, E$ and $F$, respectively all the instruments were validated by the supervisory team and the reliability was obtained by pilot testing of questionnaire and test-retest for achievement test and arrived at co-efficient alpha 0.83 and 0.81 respectively. The population was also all the public senior secondary school students in Sokoto state. A total number of twelve public senior secondary schools, with three thousand four hundred and twenty eight $(3,428)$ as the population of SS II students, were purposively selected within the six educational zones to represent the total population. Qualitative data collected were analyzed through thematic analysis by coding and transcription, while the quantitative data were analyzed using Pearson Product Moment Correlation Co-efficient. The major findings of the study were: Parental background support in relation to occupation has relationship with student's academic performance. Parental background support in relation to home environment has relationship with student's academic performance. The study recommended that: parents that are found to be of lower socio-economic status who can not provide support for the academic activities of their children, should utilize those community development programmes meant for poverty eradication and skill acquisition, such as National Poverty Eradication Programme (NAPEP), family support programme, agricultural loan scheme and so on, that will provide financial support and job security. It was also recommended that parents should endeavour to provide required academic support at home such as parental commitment and material support. That is to be fully involved in their children academic activities and to provide study facilities at home, which include teaching and learning materials. This will enhance good academic performance.
\end{abstract}

\section{Introduction}

Occupational status of parents has some influence on the academic performance of children. Hill, Castelino, Lansford, Nowlin, Dodge, Bates and Pettit (2004), pointed out that children from families with low socio-economic status are at a greater risk of hunger, homeless, sickness, physical and mental disabilities, violence, teen parenthood, family stress and educational failure. Student from low socio economic background that encounter these environmental factors are four times more likely to have learning disabilities than students from high socio economic background while a combination of these environmental factors accelerate academic success. A student, who has not eaten for days and has clothes that do not fit, cannot maintain focus in a classroom

Also Memon, Muhammad and Muhammad (2010) conducted a research on impact of parental occupation on students' educational achievements at secondary schools of District Malir, Karachi with a sample population of two hundred and forty (240) students, a descriptive survey was used based on empirical data to test the correlation among the described variables of the study. For the purpose of sampling the Malir District was divided in the four divisions, such as East, West, North and South. It was 
a purposive sample design therefore the researchers selected four (4) secondary schools ( 2 public, 2 private) from each division. Therefore, a total number of 16 secondary schools were selected randomly from male and female schools who passed matriculation from the Board of secondary education Karachi in 2004. In this way the total sample population was based on 240 students. After analysis and interpretation of the data, the research revealed that there is significant relationship between parental occupation, status and students academic performance.

However, studies indicate that there is an awareness of the importance of the home environment or family on children academic performance (Osunloye, 2008). The home has a great influence on the child's psychological, emotional, social and economic states. Ajila and Olutola (2000) observed that, the state of the home affects the individual since the parents are the first socializing agents in an individual's life. This is because the family background and context of a child affect his reactions to life situations and his level of performance. Although, the school is responsible for the experiences that make up the individuals life during school periods, yet parents and the individuals experiences at home play tremendous role in building the personality of the child and making the child what he is. Students learning and academic attainment is influenced by interplay of their individual family and school characteristics.

As investigated by Anene (2005), the influence of home environment on student's academic performance in Kitui West sub-county, Kenya. The study sought to determine the influence of parents' socio-economic status on students' academic performance. The study adopted descriptive survey design. Simple random sampling was used to select the sample of 8 principals in 8 schools, out of 28 public secondary schools, 8 PTA chairpersons in 8 selected schools out of 28 and 144 students, out of population 1440 students. Questionnaires were used for data collection. The collected data were analyzed using both descriptive and inferential statistics. The findings of the study were that the home environment influences students' academic performance $(\mathrm{r}=0.8)$, parents'/ family involvement influence students' academic performance in public secondary schools $(r=0.05)$. The ANOVA result shows there is significance relationship between mean responses of parents socio-economic status and students academic performance $\mathrm{F}\left(\mathrm{df}_{\beta}, \mathrm{df}_{\mathrm{w}}\right)=(159,1)=7.197, \mathrm{P}<0.05$, parents/family involvement and students academic performance $\mathrm{F}(93,3)=13.0, \mathrm{P}<0.05$.

Researchers had deliberated much on performance as a measure of school output For instance, Adeyemi (1998), Bandele, (2001) argued that the only measure of performance of school leavers is the attainment in GCE examinations. Consequently, they measured output in terms of the number of school leavers weighted by different indices of quality or number of passes and reported that performance in GCE is one relevant criterion of educational quality and that academic index measures output in terms of GCE results.

\section{Theoretical framework}

Conflict theorists sees as education an avenue for maintaining social inequality. Meighan and Siraj-Blatchford (2004), argued that teachers treat lower-class students like less competent students, placing them in lower "tracks" because they generally have fewer opportunities to develop language, critical thinking, and social skills prior 
to entering school than middle and upper class students. When placed in lower tracks, lower class kids are trained for blue collar jobs emphasis on obedience and following rules rather than autonomy, higher order thinking, and self expression. Likewise, children from low socio economic status will be given equal treatment as lower class students in the school and society at large, compared with those from high socioeconomic status. They point out that while private schools are expensive and generally reserved for the upper classes, public schools, especially those that serve the poor are underfunded, understaffed. Schools are also powerful agents of socialization that can be used as tools for one group to exert power over the others, For example, demanding that all students learn English, schools are ensuring that English speakers dominate students from non-English speaking backgrounds. Many conflict theorists argue, however that schools can do little to reduce inequality without broader changes in the society (e.g. creating a broader base of high paying jobs or equalizing disparities in the tax base communities). Seeing that, the problem was based on the subject of social stratification, the conflict theory was used to best explain the problem as it theoretical framework.

\section{Statement of the problem}

There are many correlates of secondary education attainment and achievement that one could look at, but in this study, the researcher has taken parental background support relation to parental occupation and home environment as these affect academic performance of their children. It has been observed by the researcher that, students of lower socio-economic families have fewer educational opportunities than those from middle and upper class families in Sokoto state, despite the current governmental effort to bring education closer to the doorstep of every Nigerian child, the effort is still facing a lot of challenges. These challenges which includes the above mentioned variables such as parental occupation and home environment, tend to bring about different types of academic experiences and different degrees of success and failure in schools in the state, there were several instances where students were exposed to such situations.

For instance, in 2013 West African Examination Council (WAEC) candidates in Sokoto state with five credits and above were $19.81 \%$ only, and $32.92 \%$ in National Examination Council (NECO) respectively.

Furthermore, in 2014, though there was a slight improvement in students' performance with $24.73 \%$ in WAEC and $47.86 \%$ in NECO yet the performance is relatively low. Most of the parents who sent their children to such secondary schools are the lower socio-economic parents. Therefore, regardless of the school's academic performance, they still need education for their children.

Thus, the main thrust of this study therefore was to examine the relationship between parental background support in relation to occupation and home environment in relation to student academic performance.

\section{Research Questions}

The research questions were: 
Is there any relationship between parental occupation and students' academic performance?

Is there any relationship between home environment and students' academic performance?

\section{Research Objectives}

The objectives of this study are:

To find out if there is any relationship between parental occupation and students' academic performance.

To find out if there is any relationship between home environment and students' academic performance

\section{Research Hypotheses}

The following Null hypotheses have been formulated to guide the study:

There is no significant relationship between parental occupation and students' academic performance.

There is no significant relationship between home environment and students' academic performance

\section{Significance of the study}

The findings of this study will help the teachers to understand the learners more closely in relation to their socio-economic background, this will enable teachers to give professional help accordingly. It will also help them to structure the teaching and learning processes in a way to enhance the intellectual and personal development of the learners. By putting into consideration the individual differences of the learners, in terms of their socio-economic background.

\section{Scope and Delimitation of the Study}

This study was delimited to only public senior secondary school students in Sokoto State, the study considered only twelve (12) public senior secondary schools, and focused only on senior secondary school students II, within the state. The choice of the SS II was based on maturity and experience, since the sampled students have been in the system for a long period of time.

\section{Research Methodology}

The research design adopted for this study was correlational research design, under the descriptive survey method that is concerned with determining or measuring the degree of relationship between two or more variables for making predictions about relationship. The population of the study is all the public senior secondary school students in Sokoto State. There are eighty (80) public senior secondary schools in Sokoto State, with a total population of eighty five thousand six hundred and forty $(85,640)$ students, and twenty two thousand, one hundred and seventy five $(22,175)$ as the total population of SS II students. 


\begin{tabular}{lll}
\hline Table 1: & \multicolumn{2}{c}{ Distribution of population by educational zones } \\
\hline Education Zones & No of schools & Total population of SS II \\
\hline Sokoto South & 19 & 8,252 \\
Sokoto North & 16 & 4,139 \\
Bodinga & 9 & 2,415 \\
Yabo & 11 & 2,055 \\
Goronyo & 14 & 2,452 \\
Gwadabawa & 11 & 1,723 \\
\hline Total & 80 & 22,175 \\
\hline
\end{tabular}

Source: $\quad$ Ministry of Education 2014

A total number of twelve (12) public senior secondary schools, with three thousand four hundred and twenty eight $(3,428)$ as the population of the SS II students, are purposively selected within the six educational zones, to represent the total population of senior secondary school students in Sokoto State. A sample of three hundred and seventy nine (379) respondents was selected using Krejcie and Morgan (1971) table for determining sample size. Subsequently, a proportionate selection of respondents was carried out in each of the selected school, The instruments used for collecting data for this study were: qualitative instruments which include focus group discussion guide, measure of academic performance, and quantitative instrument a self designed questionnaire, titled "Students Questionnaire on parental background support, in relation to occupation and home environment, both the instruments were validated by the supervisory team and some experts within and outside the faculty of education and extension services. The 20 item questionnaire was validated by the supervisory team and the reliability was obtained by pilot testing conducted in five secondary schools within Sokoto metropolis with a representative sample of sixty (60) students, whom are not part of the sample of the research. After, administering, scoring using Pearson Product Moment Correlation co-efficient, a reliability co- efficient Alpha level 0.83 was obtained. Regarding the validity of the qualitative research instrument ( Focus Group Discussion), this depend on the research's point of view and discretion bearing in mind that this study relates to the extent at which the results of the study reflects the problem he/she sought to explore and understand, while the validity of the forty (20) self designed items for the achievement tests was obtained by scrutiny, screening and corrections of the tests items by English and Mathematics teachers in secondary schools who happen to be experts in the subjects. However, the reliability of the focus group discussion (FGDs) guide became apparent after thorough vetting by the research supervisors. To obtain reliability of the achievement test, a test retest was conducted in five Secondary Schools within the metropolis with a representative sample of sixty (60) students used. The data were collected through personal visitations to the areas of study by the researcher where the three already mentioned instruments were administered.

\section{Method of Data Analysis}

The data obtained in this study were statistically analyzed to determine the relationship between parental background support in relation to occupation, home environment and students' academic performance. The data treatment and analysis of the hypotheses were done using the Statistical Package for Social Sciences (SPSS) version 20.0. 
Qualitatively, the analysis involved detailed description of data that was collected through Focus Group Discussion (FGDs), the data were transcribed into writing. The researcher gave a detailed description through analyzing by coding and classifying the data that were contained in responses. Thus, a thematic data analysis was employed to identify and analyze pattern themes and sub-themes within the data.

The quantitative data collected was analyzed using Pearson Product Moment Correlation Co-efficient, hypotheses 1 and 2, were analyzed using Pearson Product Moment Correlation Co-efficient.

\section{Quantitative presentation}

The data collected from the field was analyzed and presented below:

$\mathrm{H}_{01}$ : There is no significant relationship between parental occupation and students' academic performance.

The hypothesis was tested by subjecting the scores on parental occupation and students' academic performance to Pearson's correlation analysis as shown in table 21.

Table 2: Relationship between Parental Occupation and Students' Academic Performance

\begin{tabular}{lcclcll}
\hline Variables & $\mathrm{N}$ & Mean & $\begin{array}{l}\text { Std. } \\
\text { Deviation }\end{array}$ & r-Cal & $p$-Value & Decision \\
\hline $\begin{array}{l}\text { Parental } \\
\begin{array}{l}\text { Occupation } \\
\text { Academic } \\
\text { Performance }\end{array}\end{array}$ & 379 & 18.88 & 2.92 & & & \\
\hline
\end{tabular}

From the result of table 2, parental occupation and students' academic performance were positively related and significant, Pearson's $r(377)=.191, p=.000$. This indicates a significant relationship between parental occupation and students' academic performance because the p-value is less than the .05 level of significance. Therefore, $\mathrm{H}_{01}$ which states that there is no significant relationship between parental occupation and students' academic performance was rejected.

$\mathrm{H}_{02}$ : There is no significant relationship between home environment and students' academic performance.

The hypothesis was tested by subjecting the scores on home environment and students' academic performance to Pearson's correlation analysis as shown in table 22. 


\begin{tabular}{lllllll}
\hline Table 3: & \multicolumn{6}{c}{$\begin{array}{l}\text { Relationship between Home Environment and Students' Academic } \\
\text { Performance }\end{array}$} \\
\hline Variables & $\mathrm{N}$ & Mean & $\begin{array}{l}\text { Std. } \\
\text { Deviation }\end{array}$ & r-Cal & $p$-Value & Decision \\
\hline $\begin{array}{l}\text { Home Environment } \\
\text { Academic }\end{array}$ & 379 & 1.84 & .368 & & & \\
Performance & 379 & 17.47 & 4.68 & -.122 & .017 & $\mathrm{H}_{0}$ Rejected \\
\hline
\end{tabular}

From the result of table 3, home environment and students' academic performance though positively related were significant, Pearson's $r(377)=-.122, p=.017$. This indicates a significant relationship between home environment and students' academic performance because the p-value is less than the .05 level of significance. Therefore, $\mathrm{HO}_{2}$ which states that there is no significant relationship between home environment and students' academic performance was rejected.

\section{Qualitative presentation}

Research question one: Relationship between Parental Occupation and Students' Academic Performance.

The researcher sought to find out whether parents occupations influenced students academic performance or not. The data collected through focus group discussions with the students indicated different occupations of their parents. The occupations includes" nurses, teachers, medical doctors, carpenters, mechanics, brick layers, electricians, business men and women, peasant farmers and so on.

Respondent one made the following statement:

My father is a farmer and depend on the harvests of the farms, I am not like other students whose parents are nurses, teachers, doctors and others in public sectors I really suffer, my parent are poor and we just cultivate for feeding and little we sell for profit, it is the little money that we received my father use to pay my school demands (student, SS II age 17, Sani Dingyadi Unity Sec. Sch. Sokoto, 27-11-14).

The information from respondent one indicates low social status, low income and low self esteem from the part of the child, which are all as result of poverty level of the parents. As a peasant farmer, food is the major priority to the family. The child education is a secondary issue. Therefore, this signifies that negative achievement of students is correlated with parents' occupation, because it hinders the individual in gaining access to learning resources. The occupational level strongly affects the achievement of students, dragging them down to a lower level. It is also discovered that economically disadvantaged parents are less able to afford the cost of education of their children at higher levels, and consequently, they do not work at their fullest potential.

Respondent five, from low socio-economic background also reveals that:

If I go back home from school I will only change my uniform eat some food, and go to our shop, where I and my father serves as mechanics. I will work through out the day until 7pm when we close for the day. When I come back home, I was too tired to 
do my home work or assignment (student, SS II aged 19, Government Day Sec. Sch. Runjin Sambo, 4-12-14).

Respondent five, share the same view with respondent four. Lack of socio-economic support and involvement from the parents which negatively affect academic performance. This shows that parents' occupational level in terms of professional, semi professional, and the manual group have important relationship with their children academic performances this is because of the job mobility and child rearing practice. This should be clear that the performance of students with parents from professional group differs with the semi professional and the manual group, which is as result of the former having positive need for the academic achievement of their children.

Research Question two: Relationship between Home Environment and Students' Academic Performance.

Home environment was found to be an important factor in determining academic performance of students. From the beginning, parents have been the major persons involved in raising children in every society. That is why the family is recognized as an important agent of socialization. Through parents effort and abilities that children are socialized to become productive members of the society. So, wherever parents possess the resources and skills, and apply them effectively and joyfully in raising their children, the entire society benefits.

In this respect the study examined the availability of learning facilities such as book, desks, computers, charts, maps and electricity at home. The findings revealed that the availability of these items varied with the level of socio economic status. Parents with high socio economic status afforded to supply some of the these items to their children at home, while parents of low socio economic status can not afford. This had an impact on student academic performance.

Respondent one, from low socio economic background affirmed that:

My father is a carpenter, I live in a house without electricity and water, during the night I use kerosene lamp to revise and do home work, due to the low income of my parents, they fail to buy kerosene for us, when this happen we just sleep without doing home work or revision. On the other hand lack of water posses another challenge to me at home before doing my homework, I have to walk to the next houses so as to fetch water, this is done regularly (student, SS II age 17, Govt. day sec. sch. Shagari, 7-12-14)

The information indicated lack of parental care and support, lack of study facilities at home, and general conducive environment for learning. This affect academic performance negatively. The quotation indicates that family with low income do not create learning environment for their children. However, family with high income afford to create home learning environment by supplying books, electricity, water, maps and models. 
Respondent six, who lives in Kanwuri area also in Sokoto reveals that:

In my area we always play foot ball after school hours, we don't care to do our homework or any assignment at home because we don't have study facilities, all we do is roam about the area or go to the market for an errand, no one will tell us to go and read or do our homework, we only do that when we come to school (student, SS II aged 17, Govt. Day Sec. School Yabo, 13-12-14).

The information above shows lack of parental support and care, lack of study facilities at home, negative peer influence and general conducive atmosphere for learning. The home is the first place of learning.

The general responses of the respondents are on lack parental support, care, and encouragement, availability and unavailability of study facilities at home, positive and negative peer influence and general conducive atmosphere for learning.

\section{Summary of the Major Findings}

The following are the major findings of the study:

Parental background support in relation to occupation has relationship with student's academic performance. This implies that parents occupation which is a means of determining the socio and academic support given to children have effect on academic performance.

Parental background support in relation to home environment has relationship with students' academic performance. This implies that a home with study facilities enhanced academic performance of students.

\section{Discussion}

The finding on hypothesis one $\left(\mathrm{Ho}_{1}\right)$ led to the rejection of the statement that there is no significant relationship between parental background support in relation to occupation and students academic performance. From the result of table 1, parental occupation and students academic performance were positively related and significant, Pearson's $\mathrm{r}(377)=.191$, p-value $=000$. This indicates a significant relation between parental occupation and students' academic performance because the p-value is less than the .05 level of significance. Therefore, hypothesis $\left(\mathrm{Ho}_{1}\right)$ which states that there is no significant relationship between parental occupation and students' academic performance was rejected.

This shows a significant relationship between parental occupation and students' academic performance. This means that parents who are in civil service occupations are most likely to be supporting of their children's education so that they could achieve good results and acquire qualifications that will propel them to top positions in civil service. However it also means that parents who are in non-academic or blue collar occupations that acquire technical/vocational skills may not emphasize on paper qualification for their children as they would rather hope that children may simply perform enough to enable them acquire practical skills that will enable them to be self-employed and to stand on their own. 
The findings is in accordance with that of Memon, Muhammad and Muhammad (2010) who conducted a research on impact of parental occupation on students' educational achievements at secondary schools of District Malir, Karachi with a sample population of two hundred and forty (240) students, a descriptive survey was used based on empirical data to test the correlation among the described variables of the study. For the purpose of sampling the Malir District was divided in the four divisions, i.e. East, West, North and South. It was a purposive sample design therefore the researchers selected four (4) secondary schools ( 2 public, 2 private) from each division. Therefore, a total number of 16 secondary schools were selected randomly from male and female schools who had passed matriculation from the Board of secondary education Karachi in 2004: In this way the total sample population was based on 240 students. After analysis and interpretation of the data, the research revealed that there is significant relationship between parental occupation, status and students academic performance.

The finding on hypothesis two $\left(\mathrm{Ho}_{2}\right)$, led to the rejection of the statement that there is no significant relationship between parental background support in relation to home environment and students' academic performance. From the result of table 16, home environment and students' academic performance though negatively related were significant, Pearson's $r(377)=122, p=.017$. This indicates a significant relationship between home environment and students' academic performance because the p-value is less than the .05 level of significance. Therefore, $\mathrm{H}_{4}$ which states that there is no significant relationship between home environment and students' academic performance was rejected.

The findings is in line with that of Anene (2005) who investigated the influence of home environment on student's academic performance in Kitui West sub-county, Kenya. The study sought to determine the influence of parents' socio-economic status on students' academic performance. The study adopted descriptive survey design. Simple random sampling was used to select the sample of 8 principals in 8 schools, out of 28 public secondary schools, 8 PTA chairpersons in 8 selected schools out of 28 and 144 students, out of population 1440 students. Questionnaires were used for data collection. The collected data was analyzed using both descriptive and inferential statistics. The findings of the study were that the home environment influences students' academic performance ( $\mathrm{r}=0.8)$, parents'/ family involvement influence students' academic performance in public secondary schools $(\mathrm{r}=0.05)$. The ANOVA result shows there is significance relationship between mean responses of parents socio-economic status and students academic performance $\mathrm{F}\left(\mathrm{df}_{\beta}, \mathrm{df}_{\mathrm{w}}\right)=(159,1)=$ 7.197, $\mathrm{P}<0.05$, parents/family involvement and students academic performance $\mathrm{F}(93,3)=13.0, \mathrm{P}<0.05$.

\section{Conclusion}

Based on the data collected, analyzed and interpreted, as well as the findings, it can be concluded from the study that:

The parental occupational level is a significant factor in students' academic performance. Parent who are in civil service occupations are most likely to be supportive of their children's education, so that it will propel them to top positions in civil service. Whereas parents who are artisans or blue collar workers, may not 
emphasize on paper qualification of their children as they would rather hope that children simply perform enough to enable them acquire practical skills that will enable them to be self employed.

The quality of home environment goes a long way in determining the personality and academic performance of a child. This environment includes a home with good study facilities, the peer groups to which the learner belongs, has far reaching influence on his academic performance.

\section{Recommendations}

It is recommended that parents that are found to be of lower socio-economic status who can not provide support for the academic activities of their children, should utilize those community development programme meant for poverty eradication and skill acquisition, such as national poverty eradication programme (NAPEP), family support programme, agricultural loan scheme and so on, that will provide financial support and job security.

It is also recommended that parents should endeavour to provide required academic support at home such as parental commitment and material support. That is to be fully involved in their children academic activities and to provide study facilities at home, which include teaching and learning materials. This will enhance good academic performance. 


\section{References}

Adams, A. (1996). Even Basic Needs of Young are not met. TES. Retrieved October 8, 2008 from http://tc. Education.pitt.edu/library/self esteem.

Adeyemi, T. O. (1998). School and Teacher Variable Associated with the Performance of Students in the Senior Secondary Certificate Examination in Ondo State, Nigeria: Unpublished PhD Thesis, University of Hull, UK.

Ajila, C. \& Olutola, A. (2000). Impact of Parents' Socio-economic Status on University Students' Academic Performance. Ife Journal of Educational Studies, 7 (1): 31-39.

Anene, G. U. (2005). Home Environment and the Academic Performance of a Child, Journal of Home Economics Research, 6 (1): 99-100.

Bandele, S.O. (2001). Computer Science Education for Tertiary Institutions. AdoEkiti: Niyi commercial and printing ventures.

Ekiti State Ministry of Education (1997). Statistics of Education. Department of Planning, Research and Statistics, 3-12. Ado-Ekiti: Author.

Gery, R. W. \& Russell, B. H. (2003). Techniques to identify themes. Field methods, 15 (1): 85-109.

Hill, N. E.; Castelino, O. R.; Lansford, J. E.; Nowlin, E.; Dodge, P.; Bates, K. A. \& Pettit, G. S. (2004). Parent's Academic Involvement as Related to School Behavior, Achievement and Aspirations: Demographic Variations Across Adolescence. Child Development, 75 (5): 1491-1509.

Krejcie, R. V. \& Morgan, D. W. (1971). Determining Sample Size for Research Activities. Educational and Psychological Measurement.

Macionis, J. J. (2006). Sociology. Tenth Edition. New Delhi. Pension Inc.

Meighan R. \& Siraj-Blatchford, I. (2003). A Sociology of Educating. London: Continum.

Memon, G. R.; Muhammad, F. J. \& Muhammad, A. L. (2010). Impact of Parental Socio-economic Status on Students' Educational Achievements at Secondary Schools of District Malir, Karachi. Middle East Journal of Scientific Research, 6 (6): 678-687.

Nanalee, C. (1997). Young living (seventh edition). McGraw Hill.

Osunloye, A. (2008). Family Background and Student Academic Performance http://socyberty.com/education/family-background-and-studnet-academicperformancel. 
Ushie, M. A.; Onoghar, G. I.; Owolabi, E. O. \& Emeka, J. O. (2012). Influence of Family Structure on Students Academic Performance in Agege Local Government Area, Lagos state, Nigeria. Article in press, European Journal of Educational Studies, Turkey. 